\title{
DEVELOPING COMPUTER-BASED SCHEDULE DELAY ANALYSIS METHODS BASED ON INFORMATION FLOW ANALYSIS: A CASE STUDY
}

\author{
Ming-Kuan TSAI ${ }^{\mathrm{a}}$, Jyh-Bin YANG ${ }^{\mathrm{b}}$, Nie-Jia YAU ${ }^{\mathrm{a}}$ \\ ${ }^{a}$ Research Center for Hazard Mitigation and Prevention, National Central University, Zhongli, Taiwan \\ ${ }^{b}$ Graduate Institute of Construction Engineering and Management, National Central University, Zhongli, \\ Taiwan
}

Received 19 Oct 2011; accepted 23 Jan 2012

\begin{abstract}
Schedule analysts often resolve diverse schedule delay problems in construction projects based on their subjective experiences. Although various process-based and mathematical-model schedule delay analysis methods are available for effective schedule delay analysis, these methods require time-consuming manual operation. The use of computer-based schedule delay analysis methods seems to be a solution. However, schedule analysts still have difficulty developing computer-based schedule delay analysis methods. Therefore, this study applies information flow analysis to classify the necessary work to develop computer-based schedule delay analysis methods. In contrast to numerous studies that focus only on computerizing a process-based or a mathematical-model schedule delay analysis method, this study constructs a computer-based method that integrates two process-based schedule delay analysis methods simultaneously. In a tested case study, the delay liability for the project owner and contractor was classified successfully. Importantly, this study provides a useful reference for similar applications in project management.
\end{abstract}

Keywords: analytical techniques; claims management; construction dispute; schedule delay; programming technique; project management software.

Reference to this paper should be made as follows: Tsai, M.-K.; Yang, J.-B.; Yau, N.-J. 2013. Developing computer-based schedule delay analysis methods based on information flow analysis: a case study, Journal of Civil Engineering and Management 19(6): 823-835. http://dx.doi.org/10.3846/13923730.2013.801901

\section{Introduction}

Two questionnaire surveys (Bordoli, Baldwin 1998; Liberatore et al. 2001) indicated that more than $60 \%$ of the respondents used various project management programs for schedule planning. However, when schedule delays hinder construction projects, schedule analysts still have difficulty analyzing schedule delays, since most project management programs are infeasible for claim preparations and dispute resolution (Vidogah, Ndekugri 1998).

Recently, various schedule delay analysis methods have been developed to solve different schedule delay problems. These methods can be classified into three categories (Yang, Kao 2009):

- Process-based schedule delay analysis methods. To understand the nature of schedule delays, schedule analysts must compare different construction activities and schedules through several analysis processes. Conventional process-based schedule delay analysis methods include the global impact, net impact, adjusted as-built critical path method (CPM), as-planned expanded, collapsed but-for (termed as CBF), snapshot, time impact, windows and isolated delay type (termed as IDT) techniques (Alkass et al. 1996; Zack Jr. 2001; Arditi, Pattanakitchamroon 2006; Yang, Kao 2009);

- Mathematical-model schedule delay analysis methods. Depending on the adopted mathematical models (e.g. genetic algorithms and fuzzy sets), schedule delay analysis methods estimate the weighting values of selected delay factors to forecast how these factors cause delays in a project. For instance, Oliveros and Fayek (2005) assessed delay impacts based on a fuzzy logic approach;

- Computer-based schedule delay analysis methods. These provide numerous programs that enable schedule analysts to perform fixed functions in order to obtain analysis results efficiently. Namely, computer-based schedule delay analysis methods offer well-designed calculation tools and focus on various solutions to automate process-based methods, mathematical-model methods, or simple schedule comparison. For instance, Yates (1993) developed a construction decision support system to determine schedule delays caused by various factors. 
Based on comparison of the three methods, computerbased schedule delay analysis methods are the most effective. Such methods can assist schedule analysts in simplifying time-consuming manual operations. Moreover, various process-based and mathematical-model schedule delay analysis methods generally vary in assumptions, schedule documents, and execution processes. It is nearly impossible for schedule analysts to perform multiple process-based or mathematical-model schedule delay analysis methods simultaneously. In contrast, through computer-based schedule delay analysis methods, schedule analysts can obtain comprehensive analysis results for further claim preparation or alternative delay analysis.

However, this study still recognizes two problems when schedule analysts apply computer-based schedule delay analysis methods. Therefore, this study focuses on the procedure of implementing computer-based schedule delay analysis methods based on information flow analysis. The rest of this paper is organized as follows. Section 1 reviews studies of computer-based schedule delay analysis methods. Section 2 identifies the study problems. For these problems, Section 3 proposes an approach. Based on the approach, Section 4 develops a computer-based schedule delay method. Section 5 tests the method in a case study. Section 6 discusses several issues regarding the testing results. Conclusions are drawn in the final section, along with recommendations for future research.

\section{Literature review}

While integrating computer-based project management and schedule delay analysis, some commercial software vendors have proposed various solutions, such as the Claim Digger $^{\circledR}$ embedded in the Oracle Primavera P6 ${ }^{\circledR}$ (Oracle Corp 2011). Some commercial programs focus merely on schedule delay analysis, such as the Schedule Analyzer Professional ${ }^{\circledR}$ (Lucas 2002). Moreover, accompanying the rapid growth of process-based and mathematical-model schedule delay analysis methods, various researchers also proposed academic programs, since available commercial programs may still offer insufficient assistance, such as the results provided without transparent analytical procedures.

By investigating the correlative studies, for example, Bubbers and Christian (1992), Abudayyeh (1997), Abdul-Malak et al. (2002), Hegazy and Zhang (2005), Mbabazi et al. (2005), Iyer et al. (2008), and Yang and Tsai (2011), this study identifies three major features for computer-based schedule delay analysis methods:

- Automatic schedule delay analysis. During schedule delay analysis, schedule analysts neither compare enormous schedule information through process-based methods nor deal with complex mathematical-model methods. In contrast, even though schedule analysts do not understand the philosophy of the evaluated methods (e.g. theoretical frameworks and algorithms), they can obtain analysis results efficiently and correctly when preparing necessary delay information. For instance, Hegazy and Zhang (2005) attempted to simplify redundant manual calculation by computerizing the daily windows analysis method upon the Microsoft Excel $^{\circledR}$. While analyzing concurrent delays, Mbabazi et al. (2005) implemented the modified but-for method upon the Microsoft Project ${ }^{\circledR}$. Yang and Tsai (2011) automated the ICBF method upon the Microsoft Excel, enabling schedule analysts to evaluate project delays conveniently;

- Simple operation procedure. With easy-to-use programs and efficient collection of required data, schedule analysts can focus on the analytical results. Among the evaluated methods, office programs were commonly used, such as Abudayyeh (1997), Hegazy and Zhang (2005), Mbabazi et al. (2005), and Yang and Tsai (2011). Some methods provide adequately designed user interfaces to interact with schedule analysts. For instance, Iyer et al. (2008) developed an expert system based on the Microsoft Visual Basic ${ }^{\circledR}$ to resolve time delay disputes. Through this expert system, schedule analysts can evaluate the worth of their claims;

- Rich analytical results. Among the tools adopted in previous studies, the Microsoft Office ${ }^{\circledR}$ program-based methods applied Bar Chart/Gantt Chart to illustrate analysis results. Moreover, analysis results could be represented using textual, numerical, and graphical information. For instance, Bubbers and Christian (1992) developed a hypertext claim analysis system to enable schedule analysts to access relevant information. Abdul-Malak et al. (2002) constructed a decisionsupport system based on the Microsoft Visual Basic.

\section{Study problems}

Based on the literature review, this study recognizes two problems when schedule analysts perform computer-based schedule delay analysis methods:

- Developing computer-based schedule delay analysis methods is difficult. Depending on the characteristics of the schedule delay cases, schedule analysts may select various schedule delay analysis methods to obtain beneficial analysis results, since no one schedule delay analysis method is perfect (Bubshait, Cunningham 1998). For example, Alkass et al. (1996) used different process-based schedule delay analysis methods to analyze the same schedule delay case, and received different analysis results. To resolve such a problem, schedule analysts would attempt to apply various computer-based schedule delay analysis methods in the same program. However, commercial computer-based schedule delay 
analysis methods, for example, the Microsoft Project (Microsoft Corp 2011a), Oracle Claim Digger (Oracle Corp 2011), and Schedule Analyzer Professional (2002), provide black-box analytical results instead of schedule delay analysis algorithms. Numerous computer-based schedule delay analysis methods, for example, AbdulMalak et al. (2002), Hegazy and Zhang (2005), Mbabazi et al. (2005), Iyer et al. (2008), and Yang and Tsai (2011), merely computerize either a process-based or a mathematical-model schedule delay analysis method. Therefore, integrating various computer-based schedule delay analysis methods into a program for schedule analysts is difficult. Moreover, based on the intellectual property, some commercial programs do not enable schedule analysts to revise the program codes. In other words, developing computer-based schedule delay analysis methods has certain limitations;

- There are few references for developing computerbased schedule delay analysis methods. For selecting appropriate process-based schedule delay analysis methods, Table 1 shows that various researchers have many suggestions. For instance, Bordoli and Baldwin (1998) developed a delay analysis method that consisted of ten steps. Kartam (1999) analyzed delay claims through at least twelve consecutive steps. Shi et al. (2001) used four steps to assess the influence of activity variations. Mohan and Al-Gahtani (2006) noted that an effective delay method should include eleven elements. Arditi and Pattanakitchamroon (2006) thought that a suitable schedule delay analysis method depended on four criteria. Yang and Kao (2009) identified that general delay analysis processes contained five phases.

Based on these suggestions, schedule analysts may comprehend the philosophy of the adopted process-based and mathematical-model schedule delay analysis methods. However, schedule analysts still have difficulty implementing these methods, since they may not know how to program the philosophy via what kind of tools. In contrast, if schedule analysts do not have specific skills regarding information technology, they could develop computer-based schedule delay analysis methods when they have available references.

For the two recognized problems, this study proposes an approach, that is, information flow analysis, to help schedule analysts understand the work necessary to develop computer-based schedule delay analysis methods. This approach describes the interdependencies of various information activities whose execution may cause information to be transmitted from or to particular input, internal, or output values (Bergeretti, Carré 1985). When a clear-cut classification is made of the interactive relationship between schedule analysts and computer-based schedule delay analysis methods, reaching the anticipated objective, that is, integrating several schedule delay analysis methods into a program is easy.

\section{Information flow analysis}

Figure 1 indicates the information flow between schedule analysts and computer-based schedule delay analysis

Table 1. A list for selecting process-based schedule delay analysis methods

\begin{tabular}{l|l}
\hline Researchers & \multicolumn{1}{c}{ Suggestions } \\
\hline Bordoli and Baldwin (1998) & $\begin{array}{l}\text { (1) Preparing as-planned network and classifying delays; (2) Identifying first relevant event; } \\
\text { (3) Identifying progress at delay date; (4) Updating the network; (5) Simulating the first relevant } \\
\text { event; (6) Considering mitigating action; (7) Subsequent relevant events; (8) Considering the effect } \\
\text { of omissions; (9) Conclusion; and (10) The results. }\end{array}$ \\
\hline Kartam (1999) & $\begin{array}{l}\text { (1) Maintaining effective documents; (2) Analyzing project documents; (3) Analyzing the original } \\
\text { schedule; (4) Analyzing project resources utilization; (5) Developing as-built schedule; } \\
\text { (6) Identifying delay disruption periods; (7) Analyzing impact of specific issues; (8) Identifying } \\
\text { concurrent delays; (9) Applying the contemporaneous period analysis technique; (10) Analyzing the } \\
\text { claim; (11) Summarizing various analyses; and (12) Conducting effective meetings. }\end{array}$ \\
\hline Shi et al. (2001) & $\begin{array}{l}\text { (1) Computing activity variations between as-planned and as-built schedules; (2) Computing activity } \\
\text { variations based on causes; (3) Computing activity contributions to project delay; and (4) Cause } \\
\text { analysis. }\end{array}$ \\
\hline Arditi and & $\begin{array}{l}\text { (1) Availability of information; (2) Time of analysis; (3) Capabilities of the methodology; } \\
\text { and (4) Time and funds available for analysis. }\end{array}$ \\
\hline Mohan and & $\begin{array}{l}\text { (1) Using CPM; (2) Distributing the total float; (3) Starting with the first delay; (4) Considering } \\
\text { concurrent delays; (5) Identifying the type of delay and the corresponding responsibility; } \\
\text { (6) Identifying various events; (7) Determining the cost slope; (8) Recording one-day delay events; } \\
\text { (9) Updating project schedule; (10) Proceeding one delay-day at a time until the end of the project; } \\
\text { and (11) Tabulating the analysis results. }\end{array}$ \\
\hline Yang and Kao (2009) & $\begin{array}{l}\text { (1) Preparing all required documents; (2) Identifying impacted delay events; (3) Adopting the } \\
\text { available and reliable delay analysis methodology; (4) Clarifying the schedule impact; and } \\
\text { (5) Summarizing all analysis results. }\end{array}$ \\
\hline
\end{tabular}


methods. This flow consists of information processes, information components, and information coding.

When schedule analysts perform computer-based schedule delay analysis methods, two information processes occur. One information process is data preparation, since schedule analysts import delay data into the methods. Depending on the requirement of the adopted process-based and mathematical-model schedule delay analysis methods, the data preparation involves collecting and organizing various schedule documents, for example, as-planned and as-built schedules. The other information process is delay analysis. Through this process, the methods export analysis results for the schedule analysts. For the delay analysis, systematic process-based and mathematical-model schedule delay analysis methods facilitate the implementation of computer-based schedule delay analysis methods. The adopted methods should involve several advantages, such as dynamic schedule delay analysis methods, identification of concurrent delays, consistency for computation, and consideration of the feasibility of computerization.

Figure 1 also shows that at least four major information components are necessary for the data analysis, including analysis scenario (e.g. a baseline for schedule delay), activity-scenario relationship (e.g. analytical status), delay liability (e.g. excusable or non-excusable delay), and analysis results (e.g. the delay proportion for project participants). Since the four information components are dependent, the results of any information component would influence other information components. For example, based on various analysis scenarios, since the activity-scenario relationship changes, the delay liability is estimated. The final analysis results would summarize the delay liability from every scenario.

Information coding is the basis of implementing the information components. This study describes the generic principles as shown in Figure 1. Based on using developed tools, computer-based schedule delay analysis methods could apply either the "Open" rule or the "Execute" rule to access and import schedule documents. During the delay analysis, computer-based schedule delay analysis methods would combine the "For-Next" rule, the "If-Then" rule, and various mathematical functions to achieve the algorithms of the adopted schedule delay analysis methods. Moreover, specifying some variants and subroutines not only increase the performance of the data calculation, but also simplify the maintenance of the constructed methods in future. The "Save-As" rule or the "Save" rule could store the analysis results into a report.

In sum, based on the information flow analysis, during the development of computer-based schedule delay analysis methods, schedule analysts should prepare schedule documents, and construct information components through information coding.

\section{Developing computer-based schedule delay analysis methods}

\subsection{Development tools}

This study evaluated several development tools when developing computer-based schedule delay analysis methods during information coding. Based on five indicators in Table 2, that is, price, embedded schedule delay analysis methods, exporting Bar Chart/Gantt Chart, exporting reports, and redesigning operation interfaces, this study selected the Microsoft Project ${ }^{\circledR}$ version 2007 (Microsoft Corp 2011a). The programming language is the Microsoft "Visual Basic for Applications" $\left(\mathrm{VBA}^{\circledR}\right)$ (Microsoft Corp 2011b). In comparison with other development tools, the Microsoft Project and VBA offers useful assistance, including embedded logistical rules and mathematical functions, direct Macro recording, on-line tutorial documents, and real-time debugging description.

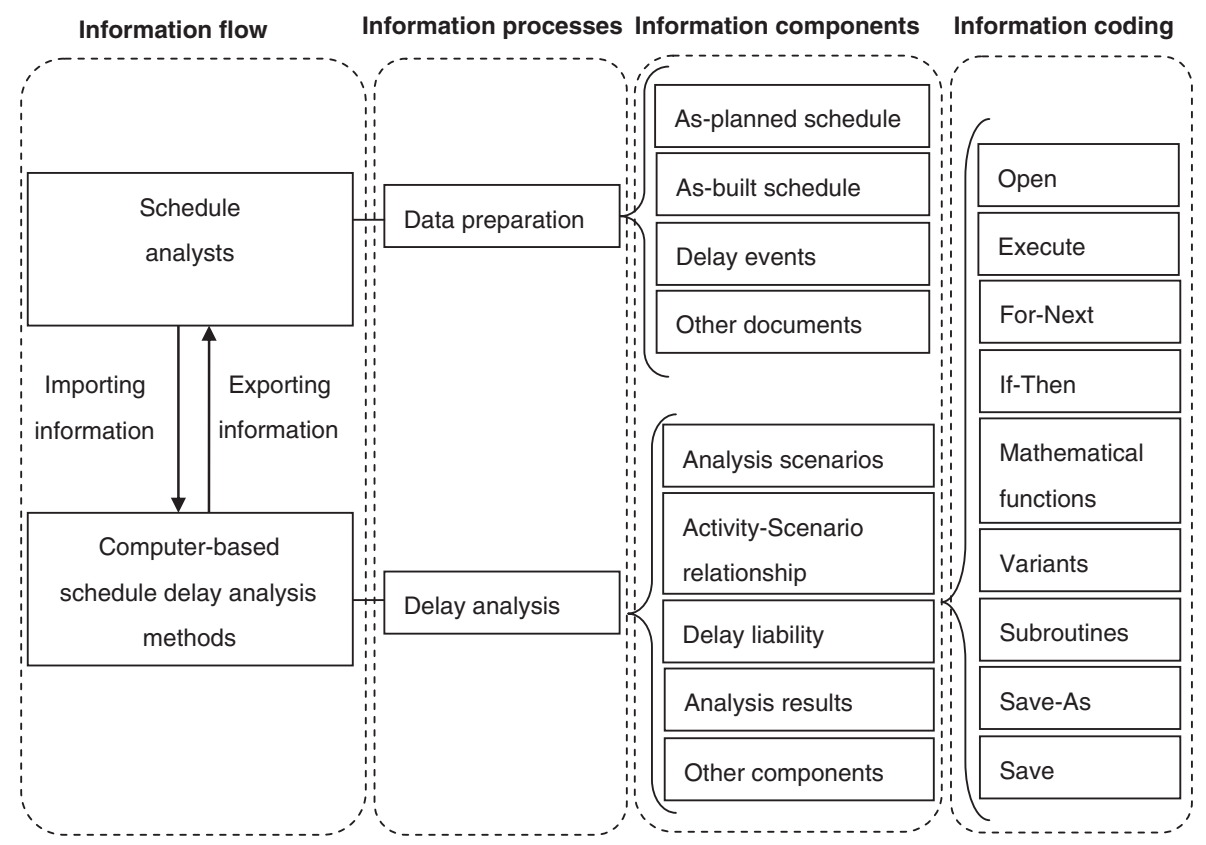

Fig. 1. Information flow between schedule analysts and computer-based schedule delay analysis methods 
Table 2. A comparison of various development tools

\begin{tabular}{|c|c|c|c|c|}
\hline & \multicolumn{2}{|c|}{ Microsoft } & \multicolumn{2}{|c|}{ Oracle } \\
\hline & Visual Studio & Excel & Project & Primavera P6 \\
\hline Programming language & $\mathrm{VB}, \mathrm{VC}++$, or $\mathrm{VC} \#$ & VBA & VBA & 一 \\
\hline Price & $\$ 549$ & $\$ 139.99$ & $\$ 599.95$ & $\$ 2500$ \\
\hline $\begin{array}{l}\text { Embedded schedule } \\
\text { delay analysis methods }\end{array}$ & No & No & CPM & Claim digger \\
\hline $\begin{array}{l}\text { Exporting bar chart/gantt } \\
\text { chart }\end{array}$ & Manual & Manual & Automatic & Automatic \\
\hline Exporting reports & Manual & Manual & Automatic & Automatic \\
\hline $\begin{array}{l}\text { Redesigning operation } \\
\text { interfaces }\end{array}$ & Yes & No & No & No \\
\hline
\end{tabular}

Despite their lack of proficiency in the Microsoft VBA, schedule analysts still can complete the information coding by revising the recorded Macro codes. Schedule analysts saved much time on designing the user interfaces because the Microsoft Project is the most adopted project management program (Fox, Spence 1998). Finally, schedule analysts receive textual, numerical, or graphical analysis results when performing the information processes. To reach the best effectiveness of project management, schedule analysts could also integrate the developed computer-based schedule delay analysis methods with the existing projects in the Microsoft Project.

\subsection{Importing information into computer-based schedule delay analysis programs}

During the data preparation, schedule analysts must understand what schedule documents are necessary for a selected method. For instance, in the IDT (Alkass et al. 1996) and isolated collapsed but-for (termed as ICBF) (Yang, Yin 2009) methods, the as-planned and as-built schedules were the basic documents, while the revised schedules that represented the identified delay events were additional documents. Moreover, the delay events should be clearly attributed to excusable-non-compensable (EN), excusable-compensable (EC), and non-excusable (NE) delays. The above schedule documents and identification required several manual processes, including the computerization of paper-based schedule data and classification of recognized delays. Successfully converting and importing schedule documents into computer-based schedule delay analysis methods are the basis of data analysis, since the collected schedule documents may be stored in different file formats (e.g. text, the Microsoft Word ${ }^{\circledR}$, Excel, or Project files). The first part of Table 3 lists the example programming codes of Microsoft Project for automatic data import.

\subsection{Exporting information from computer-based schedule delay analysis methods}

\subsubsection{Identifying analysis scenarios}

To correctly trace schedule delay and judge liability distributions of owner and contractor, computer-based

Table 3. Example codes in this study

\begin{tabular}{|c|c|}
\hline Purpose & Information coding in Microsoft Project ${ }^{\mathbb{B}}$ \\
\hline Importing schedule documents & $\begin{array}{l}\text { Filedir = Dir("C:I") } \\
\text { Application.FileOpenEx (filedir \& "built.mpp") }\end{array}$ \\
\hline Identifying analysis scenarios & $\begin{array}{l}\text { For } i=1 \text { To } 8 \\
\text { If ActiveProject.Tasks(i).Text1 = "cp1" Then } \\
\text { Sum } 1=\text { Sum1 } 1 \text { ActiveProject.Tasks(i).Number3 } \\
\text { End If } \\
\text { Next } \\
\ldots\end{array}$ \\
\hline $\begin{array}{l}\text { Classifying activity-scenario } \\
\text { relationship }\end{array}$ & $\begin{array}{l}\text { For } i=1 \text { To } 8 \\
\text { If ActiveProject.Tasks(i).Number } 1<30 \text { And } \_ \text {ActiveProject.Tasks(i).Number } 2<41 \text {. Then } \\
\text { ActiveProject.Tasks(i).Number3 = "1" } \\
\text { End If } \\
\text { Next } \\
\ldots\end{array}$ \\
\hline Estimating delay liability & $\begin{array}{l}\text { For } i=1 \text { To } 8 \\
\text { ActiveProject.Tasks(i).Number6=ActiveProject.Tasks(i).Number4___ ActiveProject.Tasks(i).Number5 } \\
\text { Next } \\
\ldots\end{array}$ \\
\hline Reporting analysis results & ActiveProject.SaveAs ("report.mpp") \\
\hline
\end{tabular}


schedule delay analysis methods required clear analysis baselines. Each analysis baseline corresponded to an analysis scenario that consisted of a start time-point and an end time-point. The principle for selecting analysis scenarios involved critical path(s) changed, major delay start and end dates, and periodic times (e.g. monthly, bimonthly, and seasonally) (Yang, Yin 2009). This study compared various activities that existed in the critical paths, and acquired the start and end time-points to identify the formed analysis scenarios. According to the second part of Table 3, this study applied the "For-Next" and "If-Then" rules of Microsoft VBA when performing the information coding.

\subsubsection{Classifying activity-scenario relationship}

When analysis scenarios were identified, computer-based schedule analysis methods examined the activities in these scenarios and determined the delay extent. In other words, when an activity was involved in an analysis scenario, computer-based schedule analysis methods should recalculate the details of the activity. If the activity was not involved in the analysis scenario, the details of the activity would be inherited from the as-planned schedule, the asbuilt schedule, or the previous analysis scenario. The "baseline schedule development" algorithm in the ICBF method (Yang, Yin 2009) could be a helpful reference, since some process-based and mathematical-model schedule delay analysis methods did not offer any algorithm to classify such relationship (e.g. the CBF and IDT methods). The third part of Table 3 displays the example programming codes. The "For-Next" rule was used here to investigate the activity-scenario relationship, and synchronously embedded the "If-Then" rule to represent the analysis results.

\subsubsection{Estimating delay liability}

Following identification of the analysis scenarios and activity-scenario relationship, computer-based schedule delay analysis methods estimated the delay liabilities for project owners and contractors. Because the EN, EC, and NE delays either impacted the as-planned schedule or occurred in the as-built schedule, computer-based schedule delay analysis methods should deal with these delays based on the adopted process-based and mathematical-model schedule delay analysis methods. For instance, the process-based IDT method incorporated the EN, EC, and NE delays that were encountered within the analysis scenarios into the as-planned schedule (Alkass et al. 1996). Moreover, based on the as-built schedule, the process-based ICBF method applied the "liability calculation" algorithm, that is, consisting of seven equations, to complete the analysis (Yang, Yin 2009). The fourth part of Table 3 indicates that this study applied several embedded mathematical functions (e.g. the "maximum" and "summary" functions) to resolve complex mathematical calculation problems.

\subsubsection{Reporting analysis results}

Computer-based schedule delay methods could either show the analysis results immediately when each information component is executed or summarize the analysis results into a report. Therefore, schedule analysts comprehended the analysis scenarios, critical activity path(s), start, and end time-points, anticipated and analytical project completion durations, and delay liability. The fifth part of Table 3 shows the example programming codes of Microsoft Project for storing the analysis results.

\section{Testing a developed computer-based schedule delay analysis method}

Based on the proposed information flow analysis, this study developed a computer-based schedule delay analysis method integrated with the process-based IDT and ICBF methods. This method analyzed a revised delay case (Alkass et al. 1996; Yang, Yin 2009), which consisted of ten activities (Activities A-J). Table 4 summarizes the project details. The anticipated completion time in the asplanned schedule was 23 days and the anticipated completion time in the as-built schedule was 35 days. There were 12 days of project delays $(35-23=12)$. By investigating the analytical procedure and analysis results, this study demonstrated that the developed method classified the liability distribution accurately for the project owner and contractor.

\subsection{Importing information into the developed method}

The developed method enabled schedule analysts to select the schedule delay analysis method, that is, "IDT", "ICBF", or "Both". After the selection, two functions were offered, that is, "Start Analysis" and "Clear Data". Schedule analysts imported the necessary schedule delay data, and selected "Start Analysis" for schedule delay analysis. If schedule analysts either entered incorrect data or needed to analyze other delay cases, they could select "Clear Data".

\subsection{Exporting information from the developed method}

When receiving delay information from schedule analysts, the developed method executed the following four information components automatically and continuously: identifying analysis scenarios for the delay case, classifying the relationship among activities and scenarios, estimating delay liability for project participants, and reporting analysis results for schedule analysts.

\subsubsection{Identifying analysis scenarios for the delay case}

Figure 2 shows that the developed method categorized these activities into three critical paths $(\mathrm{CP})$ through the computer-based IDT method. There were three analysis scenarios: Scenario 1 (Days 1 to 9), Scenario 2 (Days 10 to 20), and Scenario 3 (Days 21 to 35). For the computerbased ICBF method as shown in Figure 3, there also were three analysis scenarios: Scenario 1 (Days 21 to 35), Scenario 2 (Days 10 to 20), and Scenario 3 (Days 1 to 9).

\subsubsection{Classifying the relationship among activities and scenarios}

Figures 2 and 3 show the results regarding the activityscenario relationship in the IDT and ICBF methods. This 
Table 4. Details of the tested delay case

\begin{tabular}{|c|c|c|c|c|c|c|c|c|c|c|c|c|c|c|c|c|c|}
\hline \multicolumn{3}{|c|}{ Activity } & \multicolumn{3}{|c|}{ As-planned schedule } & \multicolumn{3}{|c|}{ As-built schedule } & \multicolumn{9}{|c|}{ Delay events } \\
\hline \multirow[b]{2}{*}{ ID } & \multirow[b]{2}{*}{ Name } & \multirow[b]{2}{*}{ Predecessor } & \multirow[b]{2}{*}{ Duration } & \multirow[b]{2}{*}{ Start } & \multirow[b]{2}{*}{ End } & \multirow[b]{2}{*}{ Duration } & \multirow[b]{2}{*}{ Start } & \multirow[b]{2}{*}{ End } & \multicolumn{3}{|c|}{$\mathrm{EN}$} & \multicolumn{3}{|c|}{$\mathrm{EC}$} & \multicolumn{3}{|c|}{$\mathrm{NE}$} \\
\hline & & & & & & & & & Duration & Start & End & Duration & Start & End & Duration & Start & End \\
\hline 1 & A & - & 7 & 1 & 7 & 9 & 1 & 9 & 1 & 6 & 6 & 0 & 0 & 0 & 1 & 5 & 5 \\
\hline 2 & $\mathrm{~B}$ & - & 5 & 1 & 5 & 8 & 1 & 8 & 1 & 2 & 2 & 1 & 4 & 4 & 1 & 3 & 3 \\
\hline 3 & $\mathrm{C}$ & $\mathrm{A}$ & 7 & 8 & 14 & 11 & 10 & 20 & 0 & 0 & 0 & 2 & 18 & 19 & 2 & 16 & 17 \\
\hline 4 & $\mathrm{D}$ & $\mathrm{B}$ & 9 & 6 & 14 & 9 & 9 & 17 & 0 & 0 & 0 & 0 & 0 & 0 & 0 & 0 & 0 \\
\hline 5 & $\mathrm{E}$ & $\mathrm{B}$ & 6 & 6 & 11 & 12 & 9 & 20 & 2 & 10 & 11 & 2 & 12 & 13 & 2 & 14 & 15 \\
\hline 6 & $\mathrm{~F}$ & $\mathrm{C}$ & 4 & 15 & 18 & 6 & 21 & 26 & 0 & 0 & 0 & 2 & 23 & 24 & 0 & 0 & 0 \\
\hline 7 & G & $\mathrm{D}$ & 3 & 15 & 17 & 5 & 18 & 22 & 0 & 0 & 0 & 1 & 20 & 20 & 1 & 21 & 21 \\
\hline 8 & $\mathrm{H}$ & E & 9 & 12 & 20 & 11 & 21 & 31 & 1 & 29 & 29 & 1 & 28 & 28 & 0 & 0 & 0 \\
\hline 9 & $\mathrm{I}$ & $\mathrm{F}$ & 5 & 19 & 23 & 9 & 27 & 35 & 1 & 34 & 34 & 2 & 31 & 32 & 1 & 30 & 30 \\
\hline 10 & $\mathrm{~J}$ & $\mathrm{H}$ & 3 & 21 & 23 & 4 & 32 & 35 & 1 & 33 & 33 & 0 & 0 & 0 & 0 & 0 & 0 \\
\hline
\end{tabular}




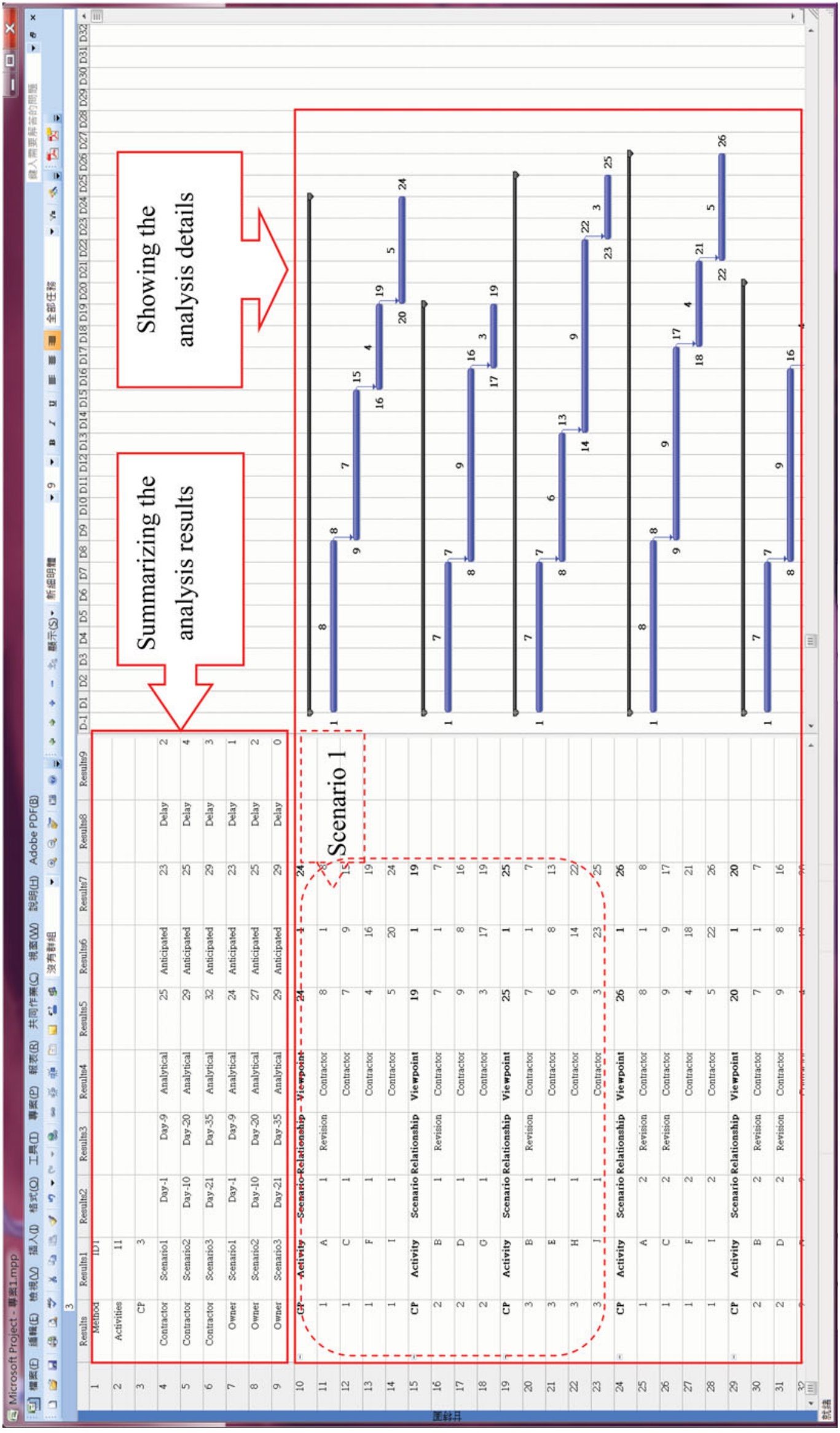

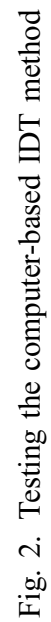




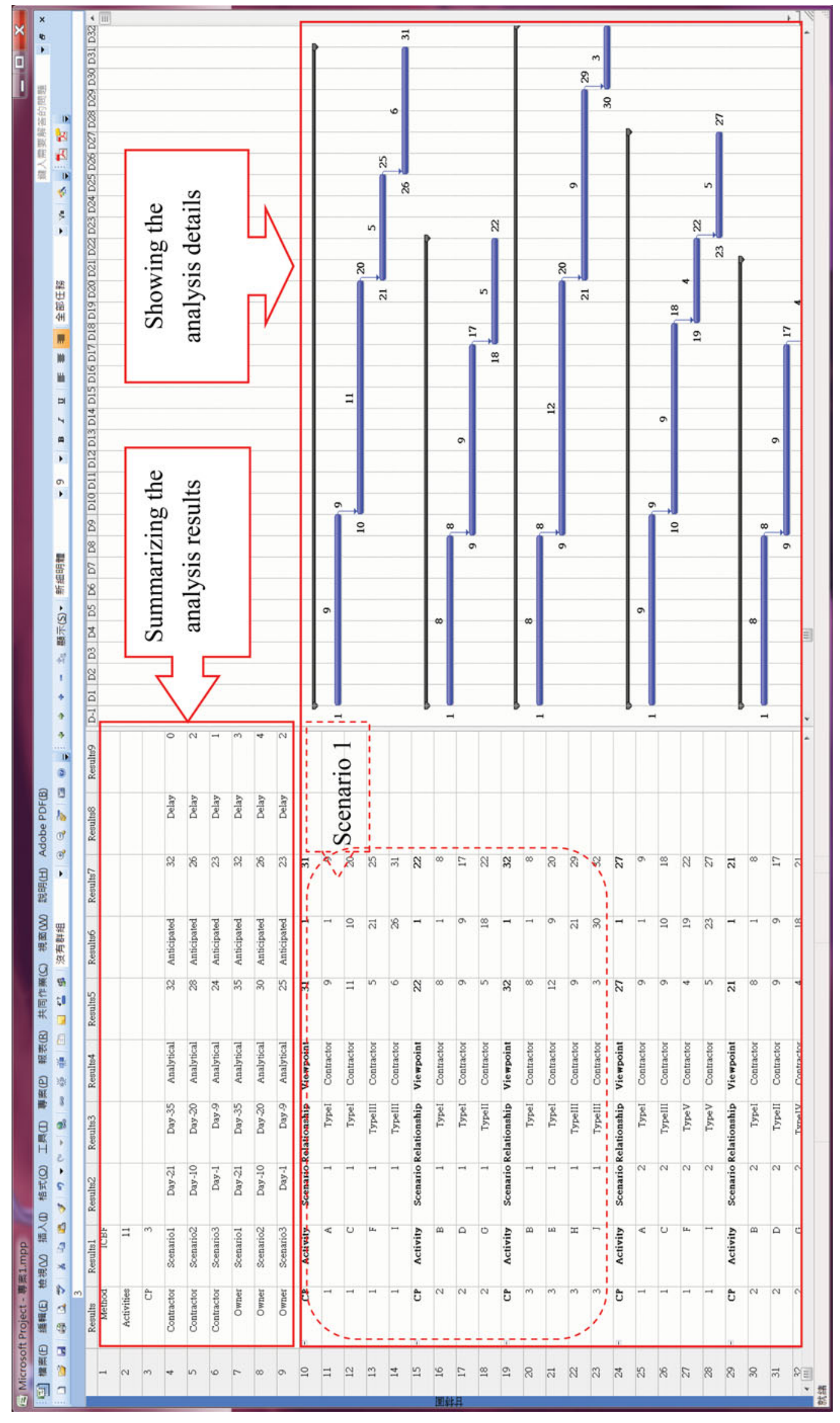

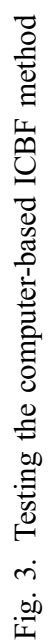


study explains how the developed method classified the relationship. For instance, when schedule analysts used the computer-based IDT method, in Scenario 1, Activities $\mathrm{A}$ and $\mathrm{B}$ finished before the end time-point so that the activity-scenario relationship for these two activities represented "Revision" as shown in Figure 2. During Scenario 1 of the computer-based ICBF method in Figure 3, Activities A to E were Type I activities, since these activities finished before the start time-point. Activity G was a Type II activity, when this activity started before the start time-point of Scenario 1 and finished within the period of Scenario 1. Activities F and H-J were Type III activities, when they both started and finished within the period of Scenario 1.

\subsubsection{Estimating delay liability for project participants}

Following successful determination of the analysis scenarios and activity-scenario relationship, the developed method estimated the delay liability. For example, in Scenario 1 of the computer-based IDT method, Figure 2 shows that Activities A and B revised their EN, EC, and NE delays. Other activities had to modify their start day and end day. After recalculation, the analytical project completion duration for the contractor and owner was 25 and 24 days, respectively. Based on Scenario 1 in the computer-based ICBF method, Figure 3 shows that Activities $\mathrm{F}-\mathrm{J}$ revised their EN, EC, and NE delays. Activities A-E were unchanged. Finally, the analytical project completion duration for the contractor and owner was 32 and 35 days, respectively.

\subsubsection{Reporting analysis results for schedule analysts}

After completing the above information components, the developed method summarized the delay liability for the contractor and owner. Figure 2 shows the analysis results in the computer-based IDT method, and Figure 3 shows that analysis results in the computer-based ICBF method. Tables 5 and 6 indicate that the anticipated project completion durations in the computer-based IDT and ICBF methods for Scenarios 1-3 were 23, 25, and 29 days and 32, 26, and 23 days, respectively. In the computer-based IDT method, comparing the analytical and anticipated project completion durations in Scenarios 1-3 revealed that the contractor and owner were delayed by 2,4 , and 3 days, and 1,2 , and 0 days, respectively. During the computer-based ICBF method, the differences for the contractor and owner in Scenarios 1-3 were 0, 2, and 1 days, and 3, 4, and 2 days, respectively. Both the computer-based IDT and ICBF methods showed 12 days of project delays. The owner caused a nine-day delay and the contractor caused a three-day delay. The contractor could claim six days $(9-3=6)$ for compensation.

\section{Discussion}

This study discussed several key issues after implementing and testing the developed computer-based schedule delay analysis method:
- Offering an effective solution for schedule delay analysis. In the tested delay case, despite the fact that the human-made calculation errors were not considered, schedule analysts spent two to three hours on manual operation through either the process-based IDT or ICBF methods. Conversely, depending on the device hardware, the developed method took merely five to ten minutes to complete the similar analysis, because the required calculations were executed automatically. Moreover, schedule analysts saved much time in obtaining both the computer-based IDT- and ICBF-based analysis results simultaneously. Clearly, developing the computer-based schedule delay analysis methods is an effective solution for schedule analysts;

- Proposing alternative philosophy for implementing computer-based schedule delay analysis methods. Rather than focusing on the usage of computerbased schedule delay analysis programs, this study presented a complete case study from understanding academic schedule delay analysis methodologies to developing a computer-based schedule delay analysis method. Based on the proposed information flow analysis, schedule analysts not only integrate numerous process-based and mathematical-model methods into the same program, but also understand to adjust the contents for complex delay cases. For example, since many process-based and mathematical-model schedule delay analysis methods have been proposed, the information components of the information flow analysis may be insufficient. Therefore, schedule delay analysts should appropriately modify the information components;

- Integrating various office programs to construct a project management information system. Different office programs provide specified functionalities for different usages and objectives. For instance, the Microsoft Project focuses on project planning and monitoring, while the Microsoft Excel focuses on the mathematical calculation. The Microsoft Word, other than the Microsoft Project and Excel, is more effective for document editing. The Microsoft Access is an appropriate database for storing project data. Through information flow analysis, project participants can effectively apply the Microsoft VBA to exchange project information among the above Microsoft Office programs.

\section{Conclusions}

Schedule delay is a contentious issue in the construction industry. Despite the increasing popularity of various schedule delay analysis methods, two main problems, that is, difficulty and insufficient references in developing computer-based schedule delay analysis methods, still adversely impact the usages of these methods. For 
Table 5. Analysis results in the computer-based IDT method

\begin{tabular}{|c|c|c|c|c|c|c|c|c|c|c|c|c|c|c|c|c|c|c|c|}
\hline \multirow{2}{*}{\multicolumn{2}{|c|}{ Period }} & \multicolumn{6}{|c|}{ Scenario 1} & \multicolumn{6}{|c|}{ Scenario 2} & \multicolumn{6}{|c|}{ Scenario 3} \\
\hline & & \multicolumn{6}{|c|}{ Days 1-9 } & \multicolumn{6}{|c|}{ Days 10-20 } & \multicolumn{6}{|c|}{ Days 21-35 } \\
\hline \multirow{2}{*}{ ID } & \multirow{2}{*}{ Activity } & \multicolumn{3}{|c|}{ Contractor } & \multicolumn{3}{|c|}{ Owner } & \multicolumn{3}{|c|}{ Contractor } & \multicolumn{3}{|c|}{ Owner } & \multicolumn{3}{|c|}{ Contractor } & \multicolumn{3}{|c|}{ Owner } \\
\hline & & Duration & Start & End & Duration & Start & End & Duration & Start & End & Duration & Start & End. & Duration & Start & End & Duration & Start & End. \\
\hline 1 & A & 8 & 1 & 8 & 8 & 1 & 8 & 8 & 1 & 8 & 9 & 1 & 9 & 8 & 1 & 8 & 9 & 1 & 9 \\
\hline 2 & $\mathrm{~B}$ & 7 & 1 & 7 & 6 & 1 & 6 & 7 & 1 & 7 & 7 & 1 & 7 & 7 & 1 & 7 & 7 & 1 & 7 \\
\hline 3 & $\mathrm{C}$ & 7 & 9 & 15 & 7 & 9 & 15 & 9 & 9 & 17 & 9 & 10 & 18 & 9 & 9 & 17 & 9 & 10 & 18 \\
\hline 4 & $\mathrm{D}$ & 9 & 8 & 16 & 9 & 7 & 15 & 9 & 8 & 16 & 9 & 8 & 16 & 9 & 8 & 16 & 9 & 8 & 16 \\
\hline 5 & E & 6 & 8 & 13 & 6 & 7 & 12 & 10 & 8 & 17 & 8 & 8 & 15 & 10 & 8 & 17 & 10 & 8 & 17 \\
\hline 6 & $\mathrm{~F}$ & 4 & 16 & 19 & 4 & 16 & 19 & 4 & 18 & 21 & 4 & 19 & 22 & 6 & 18 & 23 & 4 & 19 & 22 \\
\hline 7 & G & 3 & 17 & 19 & 3 & 16 & 18 & 4 & 17 & 20 & 3 & 17 & 19 & 4 & 17 & 20 & 4 & 17 & 20 \\
\hline 8 & $\mathrm{H}$ & 9 & 14 & 22 & 9 & 13 & 21 & 9 & 18 & 26 & 9 & 16 & 24 & 11 & 18 & 28 & 9 & 18 & 26 \\
\hline 9 & I & 5 & 20 & 24 & 5 & 20 & 24 & 5 & 22 & 26 & 5 & 23 & 27 & 8 & 24 & 31 & 6 & 23 & 28 \\
\hline 10 & $\mathrm{~J}$ & 3 & 23 & 25 & 3 & 22 & 24 & 3 & 27 & 29 & 3 & 25 & 27 & 4 & 29 & 32 & 3 & 27 & 29 \\
\hline \multicolumn{2}{|c|}{$\begin{array}{l}\text { Analytical project } \\
\text { completion days } \\
\end{array}$} & \multicolumn{3}{|c|}{25} & \multicolumn{3}{|c|}{24} & \multicolumn{3}{|c|}{29} & \multicolumn{3}{|c|}{27} & \multicolumn{3}{|c|}{32} & \multicolumn{3}{|c|}{29} \\
\hline \multicolumn{2}{|c|}{$\begin{array}{c}\text { Anticipated project } \\
\text { completion days }\end{array}$} & \multicolumn{3}{|c|}{23} & \multicolumn{3}{|c|}{23} & \multicolumn{3}{|c|}{25} & \multicolumn{3}{|c|}{25} & \multicolumn{3}{|c|}{29} & \multicolumn{3}{|c|}{29} \\
\hline \multicolumn{2}{|c|}{ Delay days } & & 2 & & & 1 & & & 4 & & & 2 & & & 3 & & & 0 & \\
\hline Sum & & & & & & & Contr & or was de & yed by & days & nd Owner & Nas del & yed by & 3 days & & & & & \\
\hline
\end{tabular}


example, schedule analysts have no ideas on using development tools to construct an effective computerbased schedule delay analysis method based on the integration of numerous process-based or mathematicalmodel schedule delay analysis methods.

To resolve these problems, this study proposed an approach, that is, information flow analysis, to present the necessary work when schedule analysts develop computer-based schedule delay analysis methods. Differing from several computer-based schedule delay analysis methods that were based on either a process-based or a mathematical-model schedule delay analysis method, this study successfully integrated the process-based IDT and ICBF methods upon the Microsoft Project. After the proposed approach was implemented, a tested case study showed that the delay liability for the project owners and contractors was classified rapidly and clearly. Obviously, the proposed approach could assist schedule analysts to systematically develop computer-based schedule delay analysis methods. Finally, this study recommends that future research identify alternatives for the major issues discussed above to increase the applicability of the developed method.

\section{Acknowledgments}

The authors would like to thank the National Science Council and National Central University, Taiwan, ROC, for financially supporting this research under Contract Nos. NSC 98-2211-E216-046, NSC 98-2811-E-216-002, NSC 99-2211-E-216-043, and NCU 100G901-11.

\section{References}

Abdul-Malak, M. A. U.; El-Saadi, M. M. H.; Abou-Zeid, M. G. 2002. Process model for administrating construction claims, Journal of Management in Engineering 18(2): 84-94. http://dx.doi.org/10.1061/(ASCE)0742-597X(2002)18:2(84)

Abudayyeh, O. Y. 1997. Multimedia construction delay management system, Microcomputers in Civil Engineering 12(3): 183-192. http://dx.doi.org/10.1111/0885-9507.00055

Alkass, S.; Mazerolle, M.; Harris, F. 1996. Construction delay analysis techniques, Construction Management and Economics 14(5): 375-394. http://dx.doi.org/10.1080/014461996373250

Arditi, D.; Pattanakitchamroon, T. 2006. Selecting a delay analysis method in resolving construction claims, International Journal of Project Management 24(2): 145-155. http://dx.doi.org/10.1016/j.ijproman.2005.08.005

Bergeretti, J.-F.; Carré, B. A. 1985. Information-flow and dataflow analysis of while-programs, ACM Transactions on Programming Languages and Systems 7(1): 37-61. http://dx.doi.org/10.1145/2363.2366

Bordoli, D. W.; Baldwin, A. N. 1998. A methodology for assessing construction project delays, Construction Management and Economics 16(3): 327-337. http://dx.doi.org/10.1080/014461998372358

Bubbers, G.; Christian, J. 1992. Hypertext and claim analysis, Journal of Construction Engineering and Management 118(4): 716-730. http://dx.doi.org/10.1061/(ASCE)0733-9364(1992)118:4 (716)
Bubshait, A. A.; Cunningham, M. J. 1998. Comparison of delay analysis methodologies, Journal of Construction Engineering and Management 124(4): 315-322.

http://dx.doi.org/10.1061/(ASCE)0733-9364(1998)124:4 (315)

Fox, T. L.; Spence, J. W. 1998. Tools of the trade; a survey of project management tools, Project Management Journal 29(3): 20-27.

Hegazy, T.; Zhang, K. 2005. Daily windows delay analysis, Journal of Construction Engineering and Management 131(5): 505-512. http://dx.doi.org/10.1061/(ASCE)0733-9364(2005)131:5 (505)

Iyer, K. C.; Chaphalkar, N. B.; Joshi, G. A. 2008. Understanding time delay disputes in construction contracts, International Journal of Project Management 26(2): 174-184. http://dx.doi.org/10.1016/j.ijproman.2007.05.002

Kartam, S. 1999. Generic methodology for analyzing delay claims, Journal of Construction Engineering and Management 125(6): 409-419. http://dx.doi.org/10.1061/(ASCE)0733-9364(1999)125: 6(409)

Liberatore, M. J.; Bruce, P.-J.; Smith, C. A. 2001. Project management in construction: software use and research directions, Journal of Construction Engineering and Management 127(2): 101-107. http://dx.doi.org/10.1061/(ASCE)0733-9364(2001)127:2 (101)

Lucas, E. D. 2002. Schedule analyzer Pro-An Aid in the analysis of delay time impact analysis, Cost Engineering 44(8): 30-36.

Mbabazi, A.; Hegazy, T.; Saccomanno, F. 2005. Modified butfor method for delay analysis, Journal of Construction Engineering and Management 131(10): 1142-1144. http://dx.doi.org/10.1061/(ASCE)0733-9364(2005)131:10 (1142)

Microsoft Corp. 2011a. Compare desktop project management versions [online], [cited 1 October 2011]. Available from Internet:

http://www.microsoft.com/project/en/us/project-2007.aspx.

Microsoft Corp. 2011b. Microsoft Developer Network [online], [cited 1 October 2011b]. Available from Internet: http://msdn.microsoft.com/en-us/isv/bb190538.

Mohan, S. B.; Al-Gahtani, K. S. 2006. Current delay analysis techniques and improvement, Cost Engineering 48(9): $12-21$.

Oliveros, A. V. O.; Fayek, A. R. 2005. Fuzzy logic approach for activity delay analysis and schedule updating, Journal of Construction Engineering and Management 131(1): $42-51$. http://dx.doi.org/10.1061/(ASCE)0733-9364(2005)131:1(42)

Oracle Corp. 2011. Oracle Aapplications [online], [cited 1 October 2011]. Available from Internet: http://www.oracle.com/applications/primavera/index.html.

Shi, J. J.; Cheung, S. O.; Arditi, D. 2001. Construction delay computation method, Journal of Construction Engineering and Management 127(1): 60-65. http://dx.doi.org/10.1061/(ASCE)0733-9364(2001)127:1(60)

Vidogah, W.; Ndekugri, I. 1998. A review of the role of information technology in construction claims management, Computers in Industry 35(1): 77-85. http://dx.doi.org/10.1016/S0166-3615(97)00085-7

Yang, J.-B.; Kao, C.-K. 2009. Review of delay analysis methods: a process-based comparison, The Open Construction and Building Technology Journal 3: 81-89. http://dx.doi.org/10.2174/1874836800903010081 
Yang, J.-B.; Tsai, M.-K. 2011. Computerizing ICBF method for schedule delay analysis, Journal of Construction Engineering and Management 137(8): 583-591.

http://dx.doi.org/10.1061/(ASCE)CO.1943-7862.0000338

Yang, J.-B.; Yin, P.-C. 2009. Isolated collapsed but-for delay analysis methodology, Journal of Construction Engineering and Management 135(7): 570-578. http://dx.doi.org/10.1061/(ASCE)CO.1943-7862.0000016
Yates, J. K. 1993. Construction decision support system for delay analysis, Journal of Construction Engineering and Management 119(2): 226-244.

http://dx.doi.org/10.1061/(ASCE)0733-9364(1993)119:2 (226)

Zack Jr., J. G. 2001. But-for schedules - analysis and defense, Cost Engineering 43(8): 13-17.

Ming-Kuan TSAI. He is an Assistant Research Fellow of Research Center for Hazard Mitigation and Prevention at the National Central University, Taiwan. His research focuses on the integration of information technology, civil engineering, construction management, and disaster management.

Jyh-Bin YANG. He is a Professor of Graduate Institute of Construction Engineering and Management at the National Central University, Taiwan. He holds project management certifications from the PMI and IPMA. He has about 200 research publications in both refereed journals, as well as conferences. He is the editor-in-chief of the Construction Management Journal (in Chinese). His research interests include construction management and project management, project scheduling and delay analysis, procurement performance evaluation and performance-based contract, knowledge management system development, and applications of AI and IT in construction management.

Nie-Jia YAU. He is a Professor of Graduate Institute of Construction Engineering and Management at the National Central University, Taiwan. He is also the Director of Research Center for Hazard Mitigation and Prevention at NCU. He has served as an arbitrator or a scheduling expert for many construction dispute cases since 1993. His research interests include schedule delay analysis, construction disputes resolution, arbitration and mediation, international construction contracts, build-operate-transfer contracts, bridge management system, and disaster prevention information system. 